\title{
MLH1 Gene Promoter Hypermethylation
} Status

National Cancer Institute

\section{Source}

National Cancer Institute. MLH1 Gene Promoter Hypermethylation Status. NCI

Thesaurus. Code C160409.

A procedure used to detect and identify hypermethylation of promoter sequences for the MLH1 gene. 